\title{
How a climate change sceptic politician changed their mind
}

\author{
Submitted for the Australian Science Communicators 2020 conference \\ By Dr Cobi Calyx and Jenny Low \\ Corresponding author: cobi.calyx@unsw.edu.au - feedback welcome
}

\section{Introduction}

Inherent in deliberative democracy is the possibility of individuals changing their position on an issue in response to persuasive communication (Dryzek 2002). This is a case study of how a person in a position of power changed their mind about climate change in response to deliberations, then used their position to put on record their thought processes in changing mind. The record of a speech from South Australian Parliament documented the politician's thought processes before and after the change. This in turn generated further dialogue in public and private spheres. This political communication indicated that the deliberative quality of a panel discussion among scientists made the reality of climate change compelling for someone who was until then a climate sceptic. The range of arguments and scientific evidence presented by the panel of diverse scientists within the consensus of climate change (van der Linden et al. 2015) persuaded the politician.

Following the speech, more detail about the circumstances that led to change emerged through civil communications among citizens, scientists, media and political actors. Some of this dialogue happened face-to-face and some in social media, which was unusually positive. This paper sheds further light on the circumstances and dialogues that led an elected representative to publicly state they had been wrong about climate change, acknowledging for the first time the need for action. Further public dialogue in response, such as deliberations about causes and the need for more such stories of change, are included with the explicit intention of this paper being a form of participatory action research (Stokols 2006). The authors were embedded in these events and dialogues and intend this artefact of documentation and reflection to support further deliberations and changes. These 'reflections from the field' may enable further stories and action to emerge, making this work part of iterative deliberations about responding to climate change. 


\section{A weekly deliberative forum on Australian television}

Detailed below is a story of change regarding politician John Darley, an elected Member of the South Australian Legislative Council, who told his staff the morning after a show was broadcast that a panel of scientists had changed his mind about climate change. The show was a special science edition of an Australian Broadcasting Corporation (ABC 2019A) weekly deliberative program called Q\&A, which has been described as an 'adventure in democracy' (Ames 2016). The show typically features a panel of politicians, though science specials have also occurred in previous years (ABC 2016). Table 1 lists the scientists involved in this panel broadcast with the percentage of time they spoke during the deliberations, as recorded by the ABC (2019A). The panellists in order of airtime were Brian Cox, Martin Van Kranendonk, Emma Johnston, David Karoly and Kirsten Banks.

Table 1. Panellists for the Q\&A Science Special and their percentage of time speaking

\begin{tabular}{|l|l|}
\hline Panellist & $\%$ of time speaking \\
\hline Brian Cox & 27 \\
\hline Martin Van Kranendonk & 26 \\
\hline Emma Johnston & 21 \\
\hline David Karoly & 17 \\
\hline Kirsten Banks & 9 \\
\hline
\end{tabular}

The program involves not only panel deliberations but also questions from citizens across Australia embedded throughout, either live from the studio audience or pre-recorded. For example, the special science episode included video questions from Aboriginal students in regional Australia, as well as instudio questions (ABC 2019A). Perceptions of the deliberative democratic value of audience questions on Q\&A depends on the political engagement of whom is asked (Eslick 2016). The potential for mass media to contribute to quality deliberations has been argued by earlier researchers (Kim et al. 2010).

Social media is another place for deliberations related to the program, particularly people responding using the \#qanda hashtag on Twitter. In contrast to the television program, the \#qanda dialogues are unframed and unmoderated - however a curated selection of these appear onscreen during the episode, becoming part of the program and associated dialogues. Twitter dialogues associated with Q\&A have been the focus of research (Dragiewicz \& Burgess 2016). In this case study, we discuss only to those tweets specifically regarding 
the politician's subsequent speech to parliament, not tweets using the \#qanda hashtag, which could be a separate focus for research in science communication.

\section{A story of deliberative impact}

On the morning of 18 June 2019, the politician declared to his staff that he now believed in climate change, due to viewing the ABC's Q\&A program which aired the night before. Staff were surprised given previous conversations had not been productive in swaying the politician's view on climate change. The politician had been in his elected position for more than a decade and throughout this period, had dismissed evidence presented by staff in favour of information selectively presented by constituents who were climate change sceptics. For example, discussions with farmers who questioned why methane emissions of cows were now being blamed for climate change when farming had been an ongoing activity, or constituents who printed content from climate sceptic websites. Notwithstanding anecdotal information provided by staff which explained why methane was now a problem, as well as offers of scientific evidence to support this, the politician was not swayed. This was despite the staff involved in these discussions having degrees in behavioural science and environmental science respectively.

The show had a positive and lasting impact on the politician, who spoke about it over the following days with staff, during which time the staff eagerly provided additional information reinforcing this new interest in the science of climate change. This information was now accepted positively. Framed in the language of deliberative democracy research, it was plural representations of climate science and climate futures voiced by scientists from different disciplines, including the scientists' divergent values and aspirations for action (Castree et al. 2014) that the politician found compelling in changing his mind. The role of 'everyday people' asking questions within the show contributed to impact, particularly one citing an influential Australian climate sceptic. How the public question shaped scientists' communication, via the program's moderator Tony Jones, is included below to give context about the show's format:

TONY JONES: True. The next question is about that. It comes via Skype. It's from Craig Roberts in Matraville, New South Wales. Craig?

CRAIG ROBERTS, MATRAVILLE, NSW: Thanks, Tony. Look, I saw the radio commentator Alan Jones on TV recently, and he said that $0.04 \%$ of the world's atmosphere is CO2. $3 \%$ of that, human beings create around the world, and of that, $1.3 \%$ is created by Australians. 
Alan's words, not mine. Is that correct? And if it's true, is human activity really making a difference?

TONY JONES: So, David, back to you to explain this, and then we'll hear from the rest of the panel. Go on.

DAVID KAROLY: Sure. So, look, Alan Jones is a very well-known radio commentator, but not everything he says is factually accurate.

TONY JONES: He did... When he was on this program, he prefaced his statements by saying, "I am not a scientist, but..."

DAVID KAROLY: Yeah.

TONY JONES: So, you ARE a scientist.

DAVID KAROLY: I AM a climate scientist, and Alan Jones is wrong. And the reason he's wrong is that, we know that, yes, the greenhouse gas concentrations in the atmosphere essentially the carbon dioxide concentration now - is 400 parts per million. And this was the one thing he was reasonably accurate on - that that corresponds to...about $0.04 \%$ of the whole of the atmosphere is made up of carbon dioxide. All his other numbers were wrong. Because we know that that carbon dioxide concentration, 100 years ago, was about 280 parts per million, or $0.028 \%$. But it's gone from 280 parts per million to 400 parts per million. It's grown 120 parts per million, or about $40 \%$, and that $40 \%$ increase is due to human activity. We know that for absolute certain. So, he's wrong about only $3 \%$ due to human activity. It's $40 \%$. And of that $40 \%$, he's right - Australians have contributed about $1.5 \%$. Now, that sounds like a small amount, but, actually, Australia only makes up $0.3 \%$ of the global population, and we're contributing $1.5 \%$, roughly, of the increase in greenhouse gases. So, is it fair that $0.3 \%$ of the global population has contributed $1.5 \%$ ? We've contributed much more than our fair share, if it was equally distributed around the world, emissions of greenhouse gases, contributing to this global warming increase in carbon dioxide in the atmosphere.

TONY JONES: OK, let's hear from some of the other panellists. Emma, you wanted to get involved.

EMMA JOHNSTON: Well, I think the point here is that this is a global issue, it's a global responsibility. And at the moment, we've got agreements... (ABC 2019A). 
The above extract from the show's transcript demonstrates some of the deliberations about climate change, which was not the only topic discussed astronomy was another focus, as well as plastic in the ocean, reflecting the areas of expertise of scientists on the panel.

In the days following the politician's change of mind, the authors of this paper met informally for coffee and discussed their areas of overlapping interest, in which the political staffer mentioned to the researcher that the politician had changed their mind about climate change after watching Q\&A, which she found somewhat frustrating given years of staff advice. The researcher congratulated the staff and politician, reassuring the staffer that their advice had laid the groundwork for the politician to be able to engage with the science of climate change presented on television. The researcher suggested that this was a fantastic opportunity to share a story of change, of interest to researchers in science communication and social change. The researcher suggested to the staffer that if there were any opportunities for the politician to discuss their change of mind in public, so that it would be on record and available for researchers to cite, it would be a valuable contribution to the public sphere (Habermas 1991).

Another outcome of this meeting was that the researcher asked the staffer for permission to communicate to one of the people on the Q\&A science panel who was in her network that her science communication work had impact. The researcher asked permission from the staffer to tweet the news that an anonymous politician had changed their mind in response to watching Q\&A, but made it clear it was up to the politician and the staff if they wished to disclose his identity in future. This communicative action (Jacobson 2003) supported deliberations among the politicians and staff about discussing his change of mind about climate change in parliament. A positive response to this from the scientist on the panel (Calyx and Johnston 2019) further contributed to the face-to-face deliberations among the politician and his staff. 


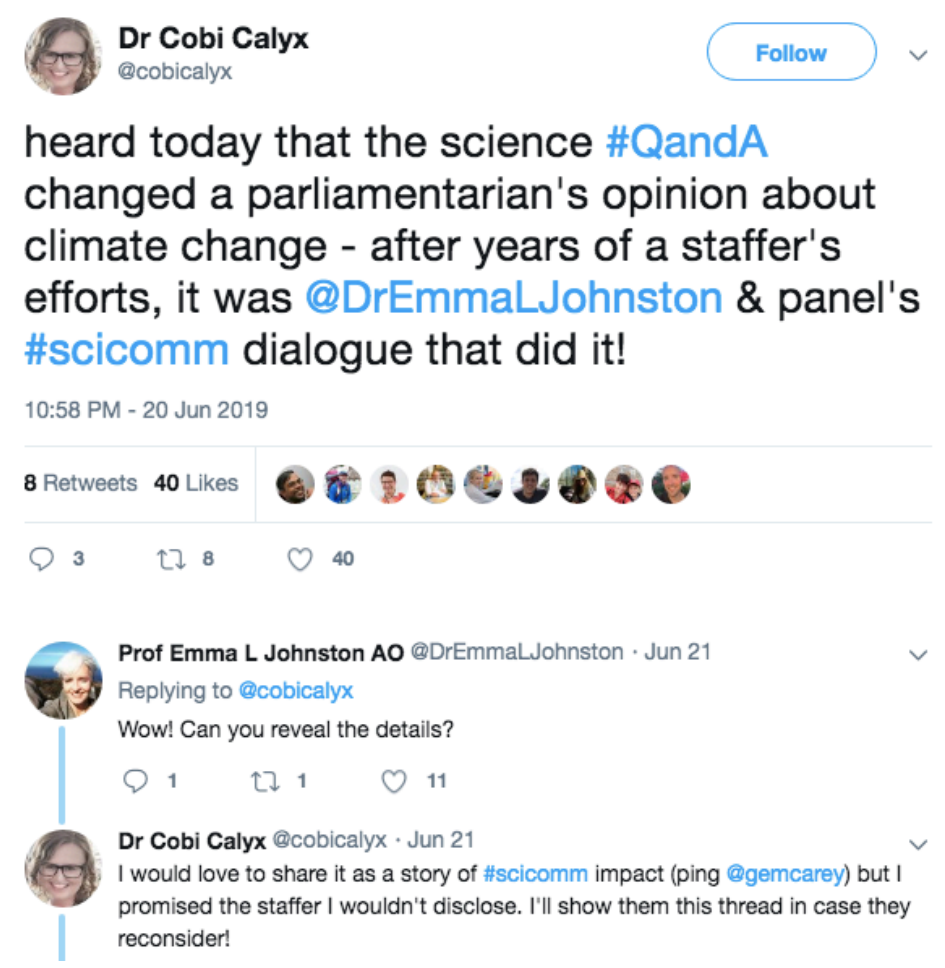

This documented interest from a researcher and one of the scientists who formed the influential panel informed deliberations between the staffers and politician about publicly conveying the politician's change of mind. This culminated in planning a speech to parliament as the subject of a Matter of Interest. Members of the South Australian Legislative Council are given five minutes to speak about any subject matter as a Matter of Interest once every few sitting weeks, with the order and frequency determined by a roster system.

Initially the environmental scientist on staff prepared a draft for the speech. This involved reviewing the material from the $\mathrm{ABC}$ broadcast as well as drawing on her knowledge and experience. The staffer also researched and interviewed the politician to better understand why he had such a resistance to the idea of climate change beforehand. The draft was then provided to the behavioural scientist on staff, who edited the speech to more strongly emphasise the attitudinal change, in particular a strong lead with it. Upon initial review of the draft speech, the politician was hesitant to make such bold statements about his previous views, however was persuaded by his staff that there was power behind the words and that the community would benefit if he were able to deliver it with the stronger message about his change of position.

The speech on 3 July at 15:27 to South Australian Parliament (2019) ensued: 
I rise today to admit that I was wrong. I believe it is important that individuals recognise their failings as well as their achievements and on the subject of climate change, I have been very wrong.

The issue of climate change has emerged over the past few decades to the point where it has become a particular focus for the community in the last few years. There have been worldwide protests which have been backed globally by scientists all urging our leaders to do something about climate change before it is too late. The matter has been widely debated with evidence plainly demonstrating that the human impact on Earth is unsustainable. However, notwithstanding all this I, I remained a sceptic.

In my 82 years on this planet I have experienced extreme weather conditions and natural disasters including droughts, floods, bushfires and earthquakes. I experienced the 1948 hurricane that destroyed the Glenelg jetty and washed away the HMAS Barcoo, in 1954, I experienced South Australia's worst earthquake and I experienced Black Sunday in 1955 and both Ash Wednesday bushfires in 1980 and 1983 respectively. These types of events have been occurring since I was a boy and I did not see a difference in these and the more recent extreme weather conditions which were being experienced globally.

In recent years the issue of climate change has been widely debated, and based on my own experiences, I believed the sceptics. I had experienced the changes in the climate and I did not believe that anything abnormal was occurring.

However on June 17 this year, the ABC's Q\&A program aired a science special. The show featured five scientists from a wide range of disciplines from astrophysicists, marine ecologists and particle physicists to geologists and climate scientists. Without a doubt, each member of the panel came to the same undeniable conclusion - that climate change is a real threat and that serious action must be taken immediately.

One might ask why the information provided in this program was so different to all the other information I had been exposed to on this subject before. Previously I had paid too much attention to climate sceptics who presented their opinions as fact. However the information given by the $\mathrm{ABC}$ was based on scientific research presented by experts in a manner which was easy to consume. They did not shy away from criticisms but instead addressed them using arguments based on actual facts not opinion.

I now understand that whilst it is true that our earth's climate has always been changing, it is the rate of change which is particularly concerning. The changes are so rapid that it is untenable for our planet. It threatens our very existence and we face extinction as a result of political inaction on climate change.

In 2016, Australia signed the Paris Agreement. Signatories pledged to strengthen the global response to climate change by maintaining this century's global temperature rise to 2 degrees with a stretch target of 1.5 degrees.

Australia's target was to reduce 2005 emissions by $26-28$ per cent by 2030 . Unfortunately, we are not only failing to be on track with this target but our emissions have been increasing since 2015 . If global emissions continue to rise at their current rate, our global temperature will rise by 1.5 degrees in just 15 years. This will have a devastating and irreversible consequence for our planet.

Naysayers often state that Australia is only responsible for contributing 1.3 per cent of global emissions however considering we only make up 0.3 per cent of the global population, our emissions are alarmingly high. Australia needs to take urgent action and commit to a target of zero percent emissions by the 2050 as the UK have done. 
I am not afraid to admit that I was a climate change sceptic. However I was wrong. I hope that my admission I will inspire other political leaders to challenge their views by turning to science instead of opinion.

This speech to parliament generated reactions from other politicians who were rebuked for applauding the speech. Whilst these responses were recorded in Hansard as an interjection, the reactions were in fact positive and made in a show of support for the politician. Members of Parliament do not typically respond to Matters of Interest, as they are not matters debated in the chamber. Interjections are not recorded in Hansard if they do not add merit or context to the proceedings, however that the interjections were supportive is relevant to this paper.

\section{Social media dialogue revealed further details about change}

The reaction following the speech was unexpected and overwhelmingly positive. Given the interest from the Q\&A panellist, the politician responded to the thread on 3 July with a link to the parliamentary speech (Darley 2019).

John Darley

@JohnDarleyMLC

Follow

Replying to @cobicalyx @DrEmmaLJohnstor

Outed...

hansardpublic.parliament.sa.gov.au/Pages/D

ateDisp ...

11:20 PM - 3 Jul 2019

7 Likes 100000

Q 1 亿

Prof Emma L Johnston AO @DrEmmaLJohnston · Jul 4

Replying to @JohnDarleyMLC @cobicalyx

Thank you John. Brave \& true.

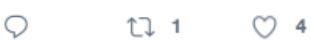

A grateful response tweet from the scientist from the Q\&A panel who'd expressed interest in knowing the politician's identity was the first of a flood of positive feedback on the politician revealing his change of mind. Table 2 below shows responses to the tweet analysed for sentiment, showing the overwhelming positivity of responses. Information about tweets that provided further information was also included in the table, in contrast to those simply giving praise or thanks or exclaiming about the change of mind. The political staffer then researcher coded the tweets as positive, negative or neutral, yielding agreed results. 
Table 2: Tweets to the politician in response to speech and content analysis

\begin{tabular}{|c|c|c|}
\hline Tweet link & Sentiment & Content type \\
\hline https://twitter.com/dan_spencer123/status/1146298766905004033?s=19 & positive & praise \\
\hline https://twitter.com/cobicalyx/status/1146676876510822401?s=19 & positive & thanks \\
\hline https://twitter.com/DrEmmaLJohnston/status/1146682787182678017?s=19 & positive & thanks \\
\hline https://twitter.com/RichardMcLellan/status/1146687725027729408?s=19 & positive & Quoting speech \\
\hline https://twitter.com/ChristieKngstn/status/1146700288079745025?s=19 & positive & praise \\
\hline https://twitter.com/KentBroad/status/1146703170074075136?s=19 & positive & praise \\
\hline https://twitter.com/ChristieKngstn/status/1146703641350295552?s=19 & positive & praise \\
\hline https://twitter.com/annarose/status/1146735890107998210?s=19 & positive & praise \\
\hline https://twitter.com/JessMedcalf/status/1146752561195540483?s=19 & positive & will show speech to grandfather \\
\hline https://twitter.com/ChristieKngstn/status/1146764230344921088?s=19 & positive & link to Q\&A bite \\
\hline https://twitter.com/healthy_climate/status/1146875530479718405?s=19 & positive & praise \\
\hline https://twitter.com/CoorongDan1/status/1146913122529054721?s=19 & positive & praise for @Q\&A expert panels \\
\hline https://twitter.com/MandyG6/status/1146924681875746816?s=19 & positive & praise \\
\hline https://twitter.com/climatecouncil/status/1146955695868149760?s=19 & positive & link to media release \\
\hline https://twitter.com/AntsyNegs/status/1146973642401538048?s=19 & positive & WA horticulturalist seeing degradation \\
\hline https://twitter.com/TonyWaugh3/status/1146995197122732033?s=19 & positive & thanks \\
\hline https://twitter.com/CarolynCrossman/status/1147008837435572224?s=19 & positive & thanks \\
\hline https://twitter.com/dejanagraziano/status/1147041496119435264?s=19 & positive & quoting speech \\
\hline https://twitter.com/ap4ca/status/1147156869850394624?s=19 & positive & climate stats \\
\hline https://twitter.com/houghton_rob50/status/1147318514513936384?s=19 & positive & call for ongoing smarter debate \\
\hline https://twitter.com/cobicalyx/status/1147387156228259840?s=19 & positive & clarification on events \\
\hline https://twitter.com/whereisdaz/status/1147390167860125696?s=19 & neutral & response to previous tweet \\
\hline https://twitter.com/BenyonMelissa/status/1148570081258921987?s=19 & positive & thanks \\
\hline https://twitter.com/a_worried_mum/status/1148690124017815552?s=19 & positive & thanks \\
\hline https://twitter.com/alphabeattweet/status/1148725042521337857?s=19 & positive & praise \\
\hline https://twitter.com/annarose/status/1148728611794382848?s=19 & positive & would like to read an article about it \\
\hline https://twitter.com/AntsyNegs/status/1148767262079193088?s=19 & positive & praise \\
\hline https://twitter.com/SalFisher19/status/1148805119967809536?s=19 & positive & link to interview with Ian Dunlop \\
\hline
\end{tabular}

This social media discussion in turn garnered attention from other twitter users including the Climate Council (2019), who published a media release about the speech which generated further social media engagement on multiple platforms. The politician received positive emails, letters and calls from constituents who offered congratulations and information on how the speech had affected them, expressing emotions from hope and intentions to share the speech with relatives. Several people representing advocacy organizations sought meetings with the politician in response, taking dialogue and collaborative learning further.

At this point, local radio stations picked up the story and quoted elements of the speech on radio news: On 8 July radio stations ABC Adelaide and ABC North 
$\&$ West included the following quote on 5pm broadcasts: "Previously I'd paid too much attention to climate sceptics who presented their opinions as fact, however the information given by the $\mathrm{ABC}$ on this program was based on scientific research presented by experts in a manner which was easy to consume" (SA Parliament 2019). The following morning on 9 July Climate Council representative Martin Rice was on the same radio stations in response to the speech, quoted at 6am and 7:45am: "We really do commend John Darley for his admission, he was wrong about climate change, so it's really important to understand that the science of climate change has long been settled, but in Australia we've seen vested interests showing doubt in people's minds". This local radio coverage led to further public responses on social media and to the parliamentary office. Twitter discussion following the speech became an interdisciplinary dialogue (Castree et al. 2014) in which decision-makers, scientists and advocates communicated about the value of honesty and changing mind in response to new understandings. The emphasis on Q\&A as the catalyst for change was countered by some social media responses with the hashtag \#ittakesavillage, which the politician also used in attributing influence to his staff who had been presenting climate change science for years. To paraphrase a proverb the politician used in publicly discussing the change, his staff had led him to water but it was the Q\&A panel that made him drink.

\section{Who had power in framing deliberations and changing mind?}

While the deliberations of the scientists on the panel were crucial to the change publicly discussed by the politician, political staffers were not the only ones contributing behind the scenes. It was the producers and researchers of the ABC (2019) Q\&A program who framed (Blue and Dale 2016) the deliberative panel, approaching and confirming the scientists who formed the panel, as well as curating the questions presented by citizens to the panel (Eslick 2016).

The politician was in a better position than most to make such a public declaration, given he was not aligned to either major Australian party and is in the twilight of his career. Research indicates that partisanship shapes perceptions of climate change (Schuldt \& 2014; Hornsey et al. 2016) and contributes to polarization (Zhou 2016); were this politician representing a party position rather than acting as an independent, this public declaration of changing position would have been less likely. In explaining his reasoning for previously being a climate change sceptic, the politician referred to a range of natural disasters he had experienced throughout his life. Highlighting these extreme weather events reflects research indicating that abnormal weather events can draw attention to climate change and help forecast long-term climate policy support (Sisco et al. 2017). Having life experience of multiple 
exceptional weather events gave the politician a frame of reference for discussing climate in public.

While the female political staffers were unable to persuade the politician about climate change, a panel of scientists in which men spoke more than two thirds of the time (ABC 2019A) proved influential. Given research demonstrating that women experience more negative online interactions (Megarry 2014) and that gender influences online responses (Chen et al. 2018), the male politician was in a position of being more likely to receive positive responses to his change of mind than women in the same position, without fear of repercussions. Even so, the overwhelming positivity of online comments was a surprise to all involved in reviewing it.

Intergenerational differences between the politician and his staffers are worthy of note, particularly given differences in intergenerational impacts of climate change (Gardiner 20016) and in the context of overwhelming public support for the politician's change of mind. Being an elected representative is a position of power, as is being of an older generation typically wielding greater political power than younger Australians (Martin 2012). While climate change was being measured once the political staffers were born, the politician had lived half his life in the era before climate change science became public knowledge (Sawyer 1972). Research indicates that older men are more likely to be climate sceptics (Tranter \& Booth 2015), suggesting generation and gender may have been related to the different positions of the politician and his staff.

Linking these demographic issues reflects content introduced to the authors of this paper via one of the tweets Table 1, from dietician Sally Fisher (2019). She linked to content from an ABC (2019B) broadcast in response to the \#schoolsstrike4climate movement (Morgan 2019), another hashtag beyond the scope of this paper but noted here to promote iterative deliberations. It is notable as these student protests led to reporting now being cited in this deliberative analysis, of relevance to deliberative democracy research about uninvited participation (Wehling 2012). An ABC (2019B) business program covered calls from the schools strike movement to spread to workers through interviewing another elderly white man, former head of the Australian Coal Association Ian Dunlop, who now calls for strong action on climate change. Research about intergenerational power imbalances was reflected in student protests covered on a business program via an interview with an elderly man, who denounced the lack of business leadership about climate change and called for emergency action. 


\section{Conclusion}

These reflections from the field of politics and science communication demonstrate aspects of the current state of public deliberations about responding to climate change in Australia. Embedded are discussions about how Australia contributes disproportionately to greenhouse gas emissions, demonstrating the global value of work towards change in Australian politics and society. Readers of this participatory action research are invited to contribute to iterative, deliberative processes of responding to climate change through their own practice.

\section{References}

ABC (2016) A special science edition of $Q \& A$ https://tv.press.abc.net.au/a-special-science-edition-of-qa

ABC (2019A) Q\&A Science Special. Accessed online 30 July 2019 at: https://www.abc.net.au/qanda/2019-17$\underline{06 / 11191192}$

ABC (2019B) The Business. Extended interview with Ian Dunlop. Accessed online 30 July 2019 at: https:/www.abc.net.au/news/programs/the-business/2019-07-08/extended-interview-with-iandunlop/11290026? jwsource $=\mathrm{cl}$

Ames, K. (2016). Being a 'Host'or a 'Journalist': Orientation to role on the ABC' s Q\&A. Discourse, Context \& Media, 11, 19-26.

Blue, G. and Dale, J. (2016) Framing and power in public deliberation with climate change: Critical reflections on the role of deliberative practitioners. Journal of Public Deliberation. Vol. 12 : Iss. 1 , Article 2. https://www.publicdeliberation.net/jpd/vol12/iss1/art2

Calyx, C. and Johnston, E. (2019) Twitter thread. June 20. Accessed online 30 July 2019 at: https://twitter.com/cobicalyx/status/1141948377866784768

Castree, N., Adams, W., Barry, J., Brockington, D., Büscher, B., Corber, E., Demeritt D., Duffy, R., Felt, U., Neves, K., Newell, P., Pellizzoni, L., Rigby, K., Robbins, P., Robin, L., Rose, D., Ross, A., Schlosberg, D., Sörlin, S., West, P., Whitehead, M., \& Wynne, B. (2014). Changing the intellectual climate. Nature Climate Change. doi:10.1038/NCLIMATE2339

Chen, G. M., Pain, P., Chen, V. Y., Mekelburg, M., Springer, N., \& Troger, F. (2018). 'You really have to have a thick skin': A cross-cultural perspective on how online harassment influences female journalists. Journalism, 1464884918768500 .

Climate Council (2019) It's never too late to admit you were wrong. July 5. Accessed online 30 July 2019 at: https://www.climatecouncil.org.au/resources/its-never-too-late-to-admit-you-were-wrong/

Martin, A. (2012). Political participation among the young in Australia: Testing Dalton's good citizen thesis. Australian Journal of Political Science, 47(2), 211-226.

Darley, J. ad Johnston, E. (2019, 3 July) Twitter thread. 3 July. Accessed online 30 July 2019 at: https://twitter.com/JohnDarleyMLC/status/1146665127434784768

Dragiewicz, M., \& Burgess, J. (2016). Domestic violence on \#qanda: The "Man" question in live Twitter discussion on the Australian Broadcasting Corporation's Q\&A. Canadian Journal of Women and the Law, 28(1), 211-229. 
Dryzek, J. S. (2002). Deliberative Democracy and Beyond: Liberals, Critics, Contestations. Oxford University Press.

Eslick, B. (2016). 'The moral power of the citizen questioner': scrutinizing the value of audience questions on the ABC's Q\&A. Media International Australia, 161(1), 120-131.

Fisher, S. (2019). Response in Twitter thread: Congratulations and thanks for your honesty and integrity. You earn respect by admitting mistakes. Please use your position to persuade others in positions of power to rethink their positions. Here's another leader we need to hear more from: https://www.abc.net.au/news/programs/thebusiness/2019-07-08/extended-interview-with-ian-dunlop/11290026?jwsource $=c l$. Accessed online 30 July 2019 at: https://twitter.com/SalFisher19/status/1148805119967809536?s=19

Gardiner, S. M. (2006). A perfect moral storm: Climate change, intergenerational ethics and the problem of moral corruption. Environmental Values, 15(3), 397-413.

Habermas, J. (1991). The Structural Transformation of the Public Sphere. MIT press.

Hornsey, M. J., Harris, E. A., Bain, P. G., \& Fielding, K. S. (2016). Meta-analyses of the determinants and outcomes of belief in climate change. Nature Climate Change, 6(6), 622.

Jacobson, T. L. (2003) Participatory Communication for Social Change: The Relevance of the Theory of Communicative Action, Annals of the International Communication Association, 27:1, 87-123, DOI: $\underline{10.1080 / 23808985.2003 .11679023}$

Kim, J., Wyatt, R. O., \& Katz, E. (1999). News, talk, opinion, participation: The part played by conversation in deliberative democracy. Political Communication, 16(4), 361-385.

Megarry, J. (2014, November). Online incivility or sexual harassment? Conceptualising women's experiences in the digital age. In Women's Studies International Forum (Vol. 47, pp. 46-55). Pergamon.

Morgan, E. (2019). Strike for climate movement encouraging workers to down tools and demand emergency action. 9 July. Accessed online 30 July 2019 at: https://www.abc.net.au/news/2019-07-09/climate-changestudents-strike-australian-companies-workers/11291394

Sawyer, J. S. (1972). Man-made carbon dioxide and the "greenhouse" effect. Nature, 239(5366), 23.

South Australian Parliament (2019). Legislative Council 2 July. Page 4011. Accessed online 30 July 2019 at: http:/hpssearch.parliament.sa.gov.au/Pages/DateDisplay.aspx\#/DateDisplay/HANSARD-10-

27263/HANSARD-10-27238

Schuldt, J. P., \& Roh, S. (2014). Media frames and cognitive accessibility: What do "global warming" and "climate change" evoke in partisan minds? Environmental Communication, 8(4), 529-548.

Sisco, M. R., Bosetti, V., \& Weber, E. U. (2017). When do extreme weather events generate attention to climate change?. Climatic change, 143(1-2), 227-241.

Stokols, D. (2006). Toward a science of transdisciplinary action research. American Journal of Community Pcsychology, 38(1-2), 79-93.

Tranter, B., \& Booth, K. (2015). Scepticism in a changing climate: A cross-national study. Global Environmental Change, 33, 154-164.

van der Linden, S. L., Leiserowitz, A. A., Feinberg, G. D., \& Maibach, E. W. (2015). The scientific consensus on climate change as a gateway belief: Experimental evidence. PloS One, 10(2), e0118489.

Wehling, P. (2012). From invited to uninvited participation (and back?): rethinking civil society engagement in technology assessment and development. Poiesis \& Praxis, 9(1-2), 43-60.

Zhou, J. (2016). Boomerangs versus javelins: how polarization constrains communication on climate change. Environmental Politics, 25(5), 788-811 